\title{
Room Temperature NH3 - Sensing Properties of WO3 thin films Synthesized by Microprocessor Controlled Spray Pyrolysis
}

\author{
P. Shanthini Grace ${ }^{1}$, J. Jebaraj Devadasan ${ }^{1 *}$, K. Jeyadheepan ${ }^{2}$ \\ G.Jeevarani Thangam ${ }^{1}$ \\ ${ }^{1}$ P.G Department of Physics, Pope's college, Sawyerpuram -628 251, Tamil Nadu, India. \\ ${ }^{2}$ Multifunctional Materials and Devices Lab, SASTRA University, Thanjavur-613401,Tamil Nadu, India.
}

\begin{abstract}
Tungsten trioxide thin films were deposited on glass substrates by microprocessor controlled spray pyrolysis method. The characterization and gas sensitivity of WO3 thin film sensor were investigated. The WO3 thin films were observed to be sensitive for NH3 vapor at different concentrations (5-200ppm) at room temperature. The maximum sensitivity for NH3 vapor by WO3 sensor was found at 200ppm concentration. The response $(\sim 50 s)$ and recovery $(\sim 30 s)$ were the main features of these sensors. The high sensitivity, quick response and fast recovery indicated that WO3 thin film sensors are selective for NH3 vapor when compared with ethanol, acetone and toluene vapors.
\end{abstract}

Keywords: Microprocessor controlled spray pyrolysis, NH3 sensor, Room temperature, WO3 thin film, XRD.

\section{Introduction}

Metal oxide semiconductor thin films have been widely used in gas sensors towards a wide range of gases like $\mathrm{NH} 3, \mathrm{NO} 2, \mathrm{CH} 4$ and $\mathrm{H} 2 \mathrm{~S}[1,2]$. Commercial $\mathrm{SnO} 2$ gas sensors have been extensively used to detect many gases in ppm levels. The lack of selectivity in $\mathrm{SnO} 2$ thin film gas sensors led researchers to investigate other MOS such as WO3. The sensing principle in the detection of gases is that there will be a change in electrical resistance [3]. Sensing mechanism depends highly on the operating temperature [3]. Sensing of gases like $\mathrm{NH} 3, \mathrm{NO} 2, \mathrm{CH} 4$ and $\mathrm{H} 2 \mathrm{~S}$ using WO3 thin film sensors have been reported at higher operating temperature (200o C) [4]. The reduction of operating temperature is an important factor in the manufacturing of MOS gas sensors.

Ammonia, a natural reductive gas is highly toxic with a limiting value of $25 \mathrm{ppm}$ for the exposure of 8 hrs [5]. Previously some of the researchers reported the use of WO3 thin film sensors for the detection of NH3 gas/vapor. Aravind Reghu et.al [6] reported the properties of WO3 sensors for detecting NH3 in the ppb range at the operating temp $450^{\circ} \mathrm{C}$. The gas sensing properties of nanocrystalline WO3 with platinum doping was investigated by Senguttuvan et.al [7].

Most of the MOS gas sensors operate at elevated operating temperature. This will increase the power consumption, reduce sensor life and complexity in designing gas sensor unit [8]. In the present study, WO3 thin film sensors have been prepared by advanced microprocessor controlled spray pyrolysis method [9]. To our knowledge, this is a novel attempt in studying the gas sensing properties of WO3 thin film sensor for detection of $\mathrm{NH} 3$ vapor at room temperature.

\section{Experimental Details}

Precursor solution of $0.05 \mathrm{M}$ was prepared by dissolving appropriate quantity of pure AR grade WO3 powder in $50 \mathrm{ml}$ hot ammonia solution by continuous stirring using magnetic stirrer and then diluted with deionized water to desired volume.

The cleaned substrates were then placed on the substrate heater of the spray equipment to provide proper heating with uniformity to films. The temperature controller was set to $300^{\circ} \mathrm{C}$. The ammonium metatungstate precursor solution was sprayed on the preheated glass substrates heated at a temperature $300^{\circ} \mathrm{C}$. The substrate temperature was controlled by microprocessor. Preparative parameters were optimized for the best quality WO3 thin film. Some of the samples were annealed at $500^{\circ} \mathrm{C}$ for $1 \mathrm{hr}$ and cooled down to room temperature naturally.

The gas sensing unit comprised Chromel-Alumel thermo couple, digital temperature indicator, heating plate and gas chamber. Two probe dc measurement technique was used to measure the electrical resistance in the presence of the test gas and air.

A constant voltage of 20 Volt is applied and the current passing through the sensor film was monitored in digital picoammeter. The $\mathrm{Cr}-\mathrm{Al}$ thermocouple was used to sense the operating temperature of the sensor. The output of the thermocouple was connected to a digital temperature indicator. The sensor response was measured National Conference on Current Advancements in Physics $3^{\text {rd }}$ \& $4^{\text {th }}$ February $2017 \quad 52 \mid$ Page Department of Physics, St. John's College, Palayamkottai-627 002, Tamilnadu, India. DOI 10.9790/4861-17002035256 
at room temperature. The required concentration of the target gas/vapor inside the chamber was achieved by injecting a known volume of test gas / vapor using a micro pipette.

After completing the measurement in target gas/vapor, air was allowed to enter into the chamber and the sample's resistance was measured in air. The sensor resistance was measured for different concentration of the target gas by successive exposure to test gas and air.

\section{Characterization Techniques}

The structural characterization of WO3 films were carried out using PAN alytical make, Model X'pert PRO X-ray diffractometer with $\mathrm{CuK} \alpha \quad\left(\lambda=1.5406 A^{0}\right)$ radiation in $2 \theta \overline{20^{\circ}-80^{\circ}}$ range . The optical transmittance spectra of the films were recorded on PG-T90 ${ }^{+}$UV - VIS - IR double beam spectrophotometer in the wave length range $300-900 \mathrm{~nm}$. The surface morphological study of WO3 thin films were carried out by Scanning Electron Microscope (SEM) using JSM-6390. The gas sensing properties of WO3 thin films were performed using gas sensing measurement unit available at Multifunctional Materials and Devices Lab, SASTRA University, Thanjavur.

\subsection{Structural Analysis}

\section{Results and Discussion}

Fig. 1 shows the XRD pattern of the annealed WO3 thin film. The triplet peak observed at $2 \theta$ values $23.1^{\circ}, 23.5^{\circ}$ and $24.4^{\circ}$ were related to monoclinic WO3 thin films with (002), (020), (200) planes (JCPDS: 830951). The average crystallite size was estimated to be $49.94 \mathrm{~nm}$ using the Debye-Scherrer formula.

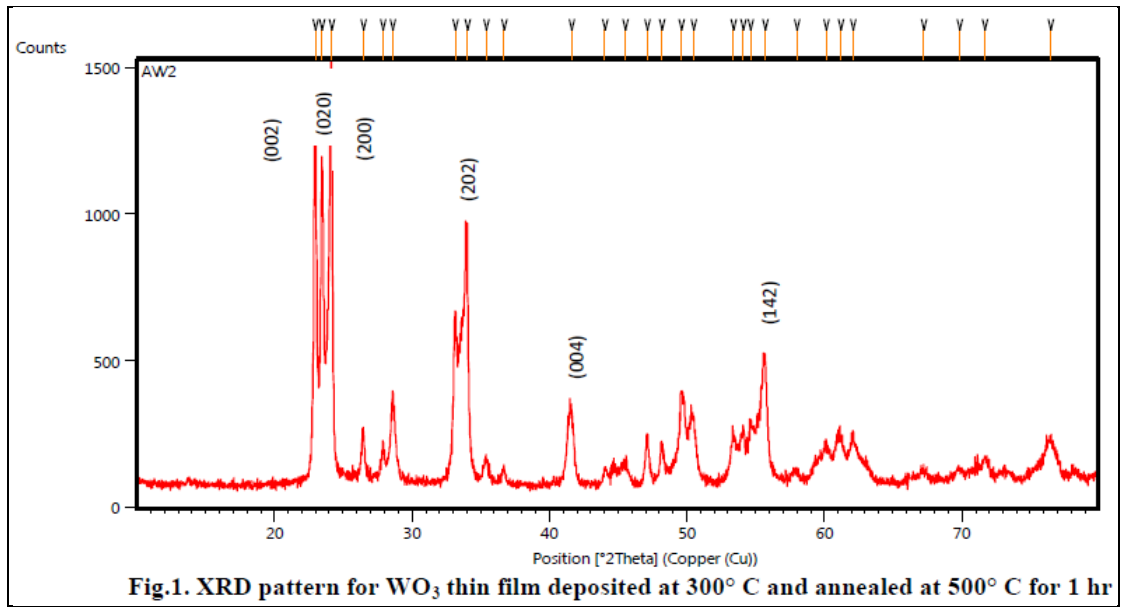

\subsection{Optical Properties}

The optical properties of WO3 thin films are determined from the transmittance spectra in the wavelength range of 300-900 $\mathrm{nm}$. The optical band gap for direct transition of as deposited WO3 thin film was obtained from Tauc plot $(\alpha h v) 2 \mathrm{vs} \mathrm{h} v$ by extrapolating the linear portion to hv axis. The optical band gap of as deposited WO3 thin film was $3.7 \mathrm{eV}$, which is in good agreement with the literature $[10,11,12]$.

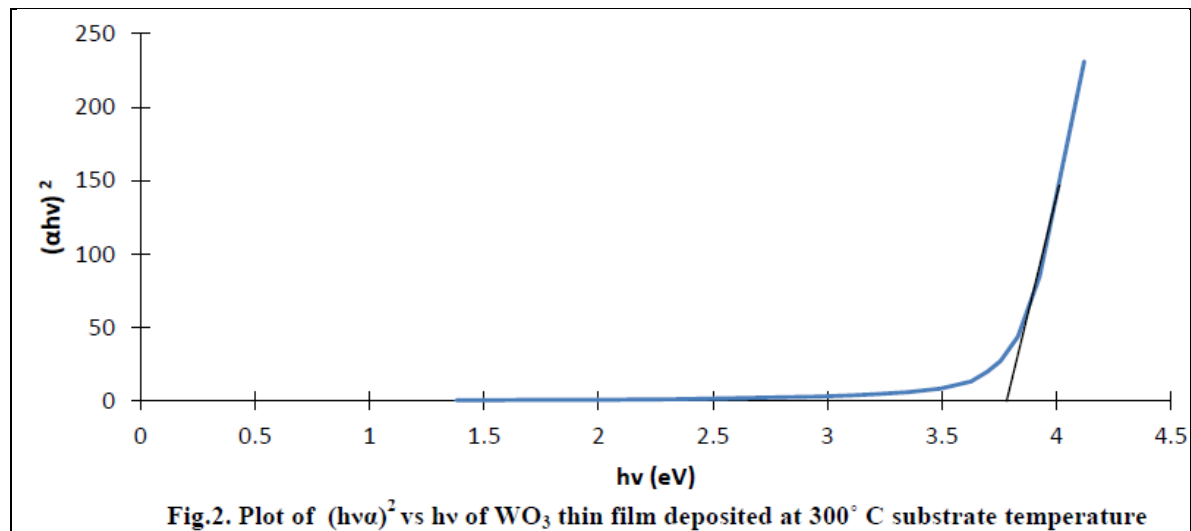

Fig.2. Plot of $(h v \omega)^{2} v s$ hv of $\mathrm{WO}_{3}$ thin film deposited at $300^{\circ} \mathrm{C}$ substrate temperature 


\subsection{Surface Morphology}

Scanning Electron Microscopy (SEM) was used for studying the surface morphology of WO3 thin films. Fig.3 exhibited the SEM image of WO3 thin film with spherical shaped grains of 380-500 nm diameter.

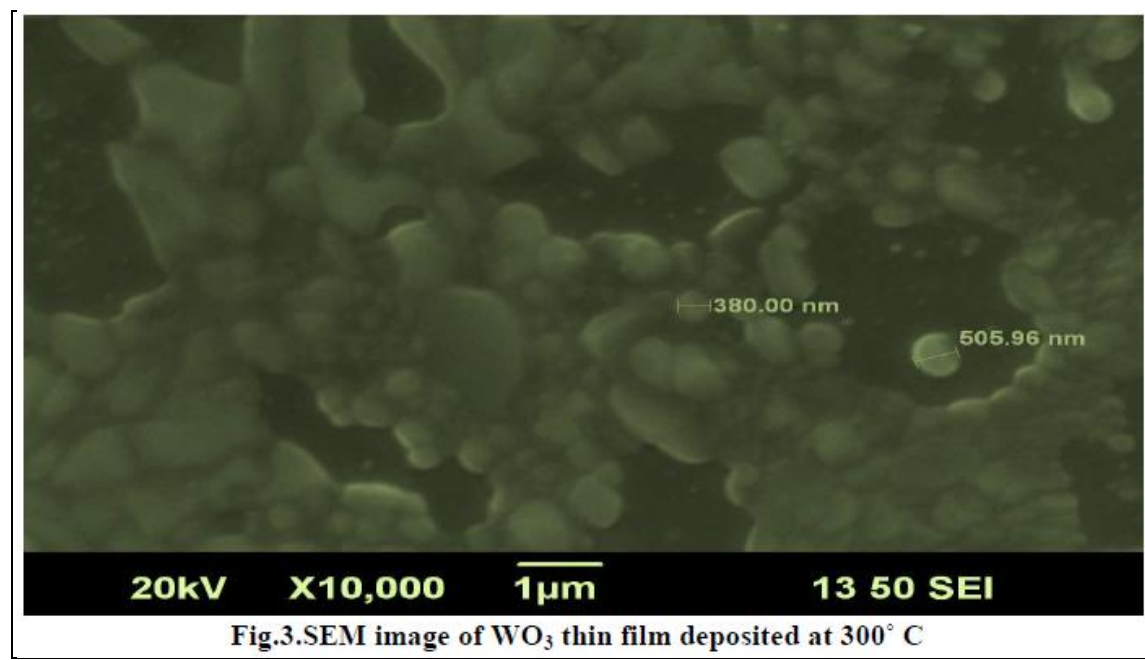

\subsection{Gas sensing properties}

The annealed WO3 thin film sensor was kept in the gas chamber to sense NH3 vapor at room temperature. The sensor element was exposed to 5, 10, 20, 50, $100 \& 200 \mathrm{ppm}$ levels of NH3 vapor. Once the exposure was completed, the sensor was allowed to recover in the flow of air. The change in current in picoammeter was measured and the corresponding change in resistance of WO3 thin film sensor was estimated.

\subsubsection{Sensitivity}

Since WO3 is a n-type semiconductor, the resistance of WO3 thin films decreased on the exposure of NH3 [6]. For reducing gas, the sensitivity of the film was calculated using the relation:

$$
\mathrm{S}=\mathrm{Ra} / \mathrm{Rg}
$$

Where, $\mathrm{S}$ is the Sensitivity, $\mathrm{Ra}$ is the resistance of the film in air and $\mathrm{Rg}$ is the resistance in test gas NH3. The sensor response curve of WO3 thin film was shown in Fig.4. The maximum sensitivity was achieved to $200 \mathrm{ppm}$ concentration of NH3. The Sensitivity of the film as a function of NH3 concentration obtained at room temperature was shown in Fig.5. Response of the film was found to be linear as the concentration increased $(5-200 \mathrm{ppm})$.

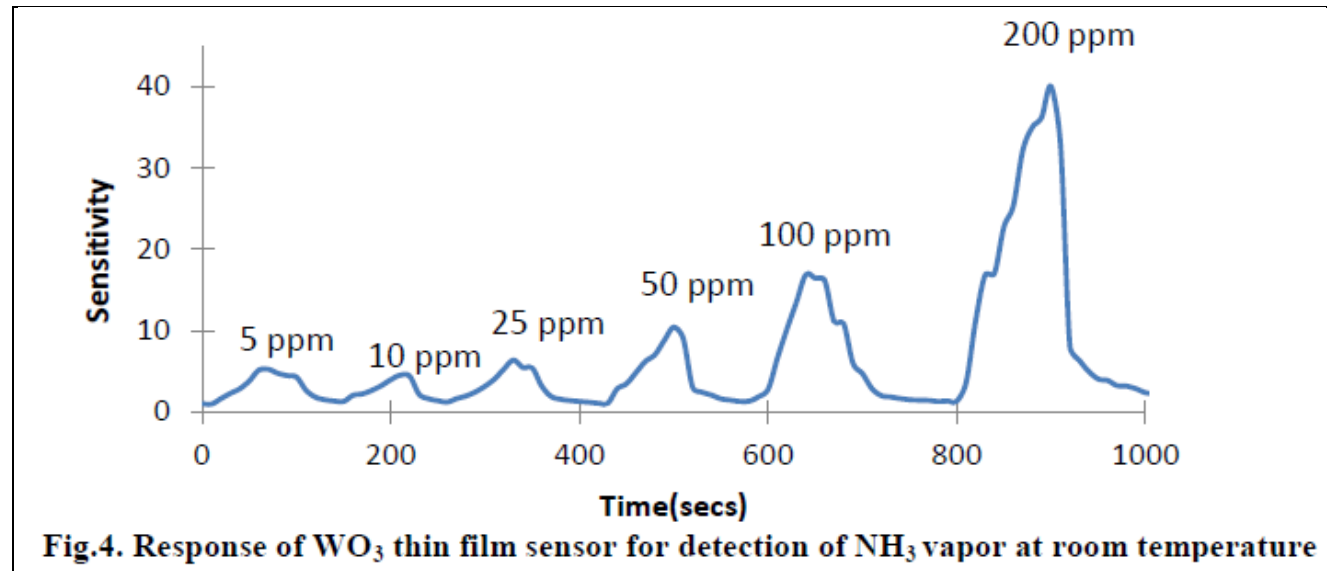




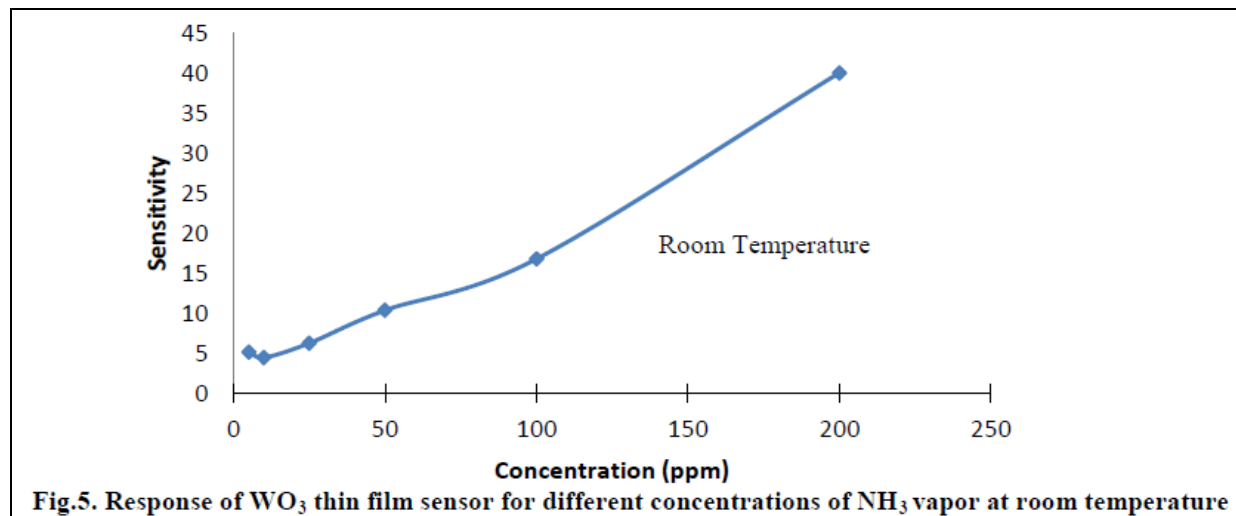

\subsubsection{Selectivity}

WO3 thin film sensor had maximum sensitivity in the detection of NH3 vapor when compared with acetone, ethanol and toluene vapors at room temperature. WO3 thin film sensor was highly selective towards NH3. Fig.6 showed the response to $\mathrm{NH} 3$, acetone, ethanol and toluene vapors at room temperature.

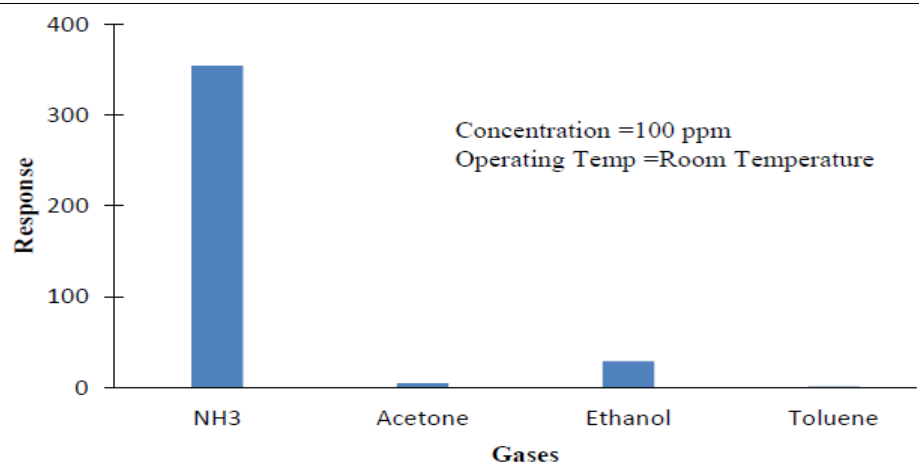

Fig.6. Response of $\mathrm{WO}_{3}$ thin film sensor to different vapors for $100 \mathrm{ppm}$ concentration at room temperature

\subsubsection{Response and Recovery Time}

The response time is defined as the time taken by the sensor to achieve $90 \%$ of the maximum sensitivity when the sensor is exposed to a test gas[13]. The recovery time is the time period over which the response of the sensor reduces to $10 \%$ of the saturation value when the sensor is exposed to air[14]. From Fig.7, we see that when $\mathrm{NH} 3$ was injected into the chamber the sensitivity increased and reached a maximum value in $50 \mathrm{sec}$ (response time). On the other hand, on removal of NH3 from the chamber, the response decreased slowly and reached its initial value after $30 \mathrm{sec}$ (recovery time).

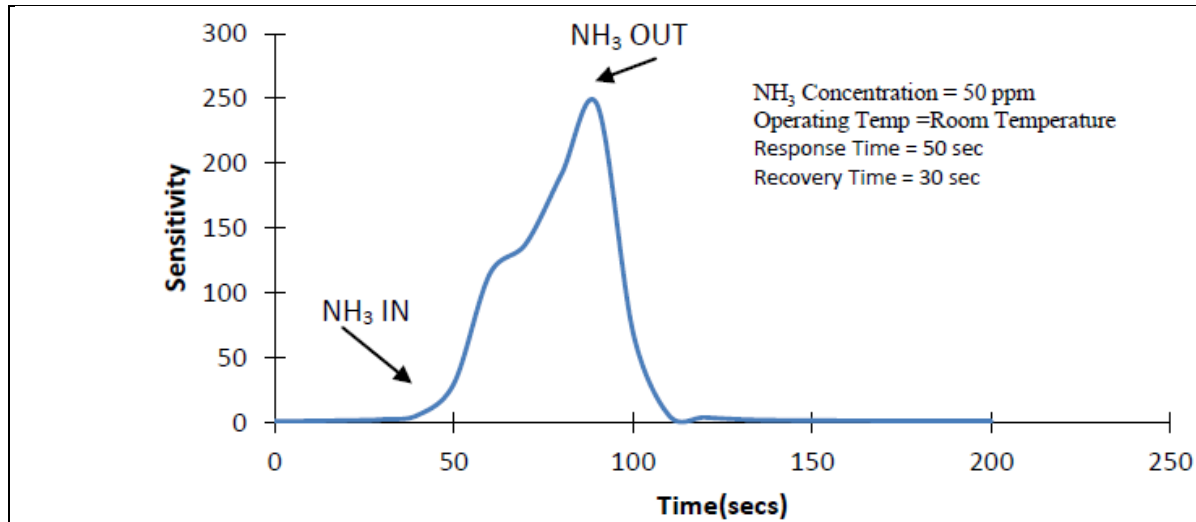

Fig.7. Response and Recovery time of $\mathrm{WO}_{3}$ thin film sensor for detection of $50 \mathrm{ppm}$ concentration of $\mathrm{NH}_{3}$ vapor at room temperature 


\section{Conclusion}

WO3 thin films were prepared by microprocessor controlled spray pyrolysis technique on glass substrates with $0.05 \mathrm{M}$ concentrations at the substrate temperature $300^{\circ} \mathrm{C}$. From X-ray diffraction spectrum, the WO3 thin films exhibited polycrystalline monoclinic structure. The average crystallite size was found to be $49.94 \mathrm{~nm}$. The direct optical band gap was estimated to be $3.7 \mathrm{eV}$ from the transmittance spectra. The surface morphology consisted of spherical grains of size $300-500 \mathrm{~nm}$.

WO3 thin film sensor was found to be very sensitive to NH3 vapor at room temperature. On the exposure of NH3 vapor, the resistance of WO3 thin film sensor was found to be decreased. The maximum sensitivity to NH3 vapor by WO3 thin film sensor was achieved at $200 \mathrm{ppm}$ concentration. WO3 thin film sensor showed quick response (50s) and fast recovery time (30s) at room temperature for the detection of $\mathrm{NH} 3$ vapor indicating that these films can be used as good sensor devices.

\section{Acknowledgement}

The author (PSG) thanks Multifunctional Materials and Devices lab, SASTRA University, Thanjavur for gas sensing measurments.

\section{Reference}

[1]. W.Gopel, Sensors and Actuators A: Physical, 56, 1996, 83-102.

[2]. G.Korotcenkov, Materials Science and Engineering: B, 139, 2007, 1-23

[3]. A. Arfaui, S. Touihri, A. Mhamdi, A. Labidi, T. Maroubi, Applied Surface Science, 357, 2015, 1089-1096.

[4]. M. Akiyama, J. Tamaki, N. Miura and N. Yamazoe, Chem.Lett., 1991, 1611.

[5]. Shashwati Sen, K.P. Muthe, Niraj Joshi, S.c. Gadkari, S.K. Gupta, Jegannath, J.V. Yakhuri, M. Roy, S.K. Deshpande, BARC Newsletter, 249, 2003, 51-56.

[6]. Aravind Reghu, Drya Deniz, RahimStennett, George Bemhardt, David Frankel, Robert Lad, John Vetelino, IMCS, 2012,457-460.

[7]. T.D. Senguttuvan, Vibha Srivastava, Jai S. Tawal, Monika Mishra, Shubhda Srivastava, Kiran Jain, Sensors and Actuators B: Chmical, 2010.

[8]. N.G. Patel, P.D. Patel, V.S. Vaishnav, Sensors and Actuators B, 96, 2003, 180-189.

[9]. P. Shanthini Grace, J. Jebaraj Devadasan, G. Jeevarani Thangam, C. Sanjeeviraja, International Journal of Chem Tech Research, 6, 2014, No.13, pp 5387-5390.

[10]. M.G. Hutchins, D. Abu-Alkhair, M.M. EI -Nahass, K. Abb El-Hady, Proc.2nd Saudi Scr. Conf. Fac.Sci.KAU, 15 17 March 2004, Part II, PP - 267 - 276 (2005 AD / 1425 A. II).

[11]. Abdoljavad Novinrooz, Masoomeh Sharbatdaran, Hassan Noorkojouri, Central European Journal of Physis, 3(3), 2005, 456 - 466. [12] T. Ivanova, K.A. Gesheva, C. Popkirov, M. Ganchev, E.Tzvetkova, Mat. Sci. Eng. B., 119, 2005, 232.

[12]. A.Wei, L.Pan, W.Huang, Materials Science and Engineering B, 2011, 1409-1421.

[13]. D.Aswal, S.Gupta, Science and technology of chemiresistor gas sensors, (Nova Science Publishers, 2006). 